\title{
Availability of Triazine Herbicides in Aged Soils Amended with Olive Oil Mill Waste
}

\author{
Alegria Cabrera, ${ }^{\dagger}$ Lucia CoX, ${ }^{*}, \dagger$ William C. Koskinen, ${ }^{*}$ And \\ Michael J. SADOWSKY ${ }^{\S}$ \\ Instituto de Recursos Naturales y Agrobiología de Sevilla IRNAS CSIC, P.O. Box 1052, \\ 41080 Sevilla, Spain, Agricultural Research Service, U.S. Department of Agriculture, 1991 Upper \\ Buford Circle, 439 BorH, St. Paul, Minnesota 55108, and Department of Soil, Water, and Climate, \\ and The BioTechnology Institute, University of Minnesota, 1991 Upper Buford Circle, \\ 439 BorH, St. Paul, Minnesota 55108
}

\begin{abstract}
Amendments are frequently added to agricultural soils to increase organic matter content. In this study, we examined the influence of alperujo, an olive oil mill waste, on the availability of two triazine herbicides, terbuthylazine and atrazine, in two different sandy soils, one from Sevilla, Spain, and the other from Minnesota. The effect of aging on herbicide sorption and bioavailability was also studied. Soils were amended with alperujo at a rate of $3-5 \%(\mathrm{w}: \mathrm{w})$ in laboratory studies. Apparent sorption coefficients for the triazine herbicides were calculated as the ratio of the concentrations of each herbicide sequentially extracted with water, followed by aqueous methanol, at each sampling time. These data showed greater sorption of terbuthylazine and atrazine in amended soils as compared to nonamended soils, and an increase in the amount of herbicide sorbed with increasing aging time in nonamended soils. The triazine-mineralizing bacterium Pseudomonas sp. strain ADP was used to characterize triazine bioavailability. Less mineralization of the herbicides by Pseudomonas sp. strain ADP was observed in soils amended with alperujo, as compared to the unamended soils, and, despite the increase in sorption with aging in unamended soils, herbicide mineralization also increased in this case. This has been attributed to Pseudomonas sp. strain ADP first using alperujo as a more readily available source of $\mathrm{N}$ as compared to the parent triazines. In summary, addition of alperujo to the soils studied was shown to increase triazine herbicides sorption and hence to reduce its availability and potential to leach.
\end{abstract}

KEYWORDS: Triazine herbicides; sorption; bioavailability; Pseudomonas sp. strain ADP; soil; alperujo; olive oil mill waste; aging

\section{INTRODUCTION}

As demonstrated by numerous studies in Europe and the United States, the use of pesticides involves a risk of potentially contaminating surface and groundwater (1-3). However, because pesticides often ensure an abundant and affordable food supply, the use of these products continues worldwide. For instance, in the United States, the amount of pesticides increased from 401500 tons of active ingredient in 1992 to 443700 tons in 1997. The amount of herbicides has also increased in the same period of time, to 207600 tons of active ingredient in 1997, with atrazine the most widely used herbicide in crops (33 600 tons) (4). Also, over the last 10 years, the US-EPA has registered many new active ingredients and new uses of pesticides (www.epa.gov/oppfead1//annual/2006/06annual-rpt.pdf).

* Author to whom correspondence should be addressed [telephone 3495462 4711; fax 3495462 4002; e-mail lcox@irnase.csic.es].

${ }^{\dagger}$ IRNAS CSIC.

¥U.S. Department of Agriculture.

$\S$ University of Minnesota.
In Europe, the use of plant protection products increased from 50000 tons in 1992 to 95000 tons in 2002, after which it decreased to 85000 tons in 2003. The use of herbicides has followed the same trend (5). The use of triazine herbicides, such as atrazine, cyanazine, simazine, and terbuthylazine, which are applied widely for weed control in a variety of crops including corn, sorghum, citrus orchards, olive groves, fruit trees, and grapes, has fallen from 5th to 12th place in a ranking of the most used chemicals in Europe. During 2003, 3624 tons of triazine herbicides was used in Europe, which represents $4.3 \%$ of the total of herbicides (5).

The decrease in triazine usage in Europe is chiefly due to legal provisions limiting the use of these products. Atrazine and simazine have been classified as priority substances by the European Parliament and the Council of the European Union in water policy Directive 2455/2001/EC. Triazine parent compounds and their microbial metabolites (the most important dissipation mechanism in soil is by microbial degradation) (6) 
have been detected in surface and ground waters in several European countries and in the United States (7-12).

It has been suggested that the use of organic amendments in soils can reduce the amounts of pesticide available for leaching to groundwater and for runoff to surface water (13). These amendments increase the organic matter (OM) content of the soil, enhancing herbicide sorption, and thereby decreasing availability for both transport and degradation processes. For instance, commercial peat used as a soil amendment increased herbicide sorption and decreased herbicide leaching as compared to humic acid-amended soil (14). Likewise, soil amended with sludge, urban waste compost, and composted straw have also been shown to increase atrazine sorption as compared to unamended soil $(15,16)$, and the latter additions were shown to decrease atrazine mineralization (16). It has also been reported that metribuzin has a lower mobility in soils amended with organic manure and with fly ash (17). Addition of organic amendments, however, does not protect against the leaching of highly water-soluble compounds or prevent the degradation of pH-sensitive compounds (18).

The extraction of oil from olives generates a large amount of organic waste. The impacts of liquid waste from olive oil extraction $(13,19)$, and the solid byproduct (alperujo) of the two-phase olive oil extraction process as organic amendments on pesticide leaching and degradation (20-22), have been recently studied. Cox et al. (13) reported that soils amended with olive-mill wastewater reduced or stopped leaching of the herbicides clopyralid (3,6-dichloropicolinic acid) and metamitron (4-amino-3-methyl-6-phenyl-1,2,4-triazin-5(4H)-one), respectively, in a clay soil, as compared to unamended soil. These authors speculated that an increase in sorption and degradation of the herbicides in the amended soil occurred via the reduction of soil porosity caused by the amendment. However, a decrease in imazaquin sorption was found in different soils amended with olive mill wastewater, except for a loamy sand soil, where herbicide sorption increased and leaching decreased (19).

When alperujo solids were used as an organic amendment in a sandy soil freshly treated with simazine, sorption was reported to increase, and leaching decrease, as compared to unamended soil $(20,21)$. Delgado-Moreno et al. (22) also found an increase in sorption and decrease in desorption of four triazine herbicides freshly applied to a soil amended with alperujo as compared to unamended soil; however, the magnitude of the increase in sorption decreased if the soil amended with alperujo had been aged for months prior to treatment with the triazines. Albarrán et al. $(20,21)$ also found that simazine dissipation in freshly treated soil was shown to be initially slower in the unamended soil as compared to amended soil, as characterized by solvent extractability, presumably due to increased sorption. However, after $30 \mathrm{~d}$ of incubation, simazine dissipation was faster in the unamended soil than in the amended soil, as shown in part by the decrease in simazine mineralization in the alperujo amended soil. Similarly, Farenhorst et al. (23) reported that there was less mineralization of 2,4-D (2,4-dichlorophenoxy acetic acid) in soils amended with biosolids or with manure as compared to the original soils.

In the studies described here, we examined the effect of alperujo amendment on the availability of terbuthylazine and atrazine, two triazine herbicides widely used for weed control, for transport, and for degradation in two sandy soils. The availability of parent triazine for transport was characterized using sequential solvent extraction techniques to determine sorption in freshly treated and aged unamended and amended soils. Characterization of bioavailability of freshly treated and aged parent terbuthylazine and atrazine residues in alperujoamended and unamended soils was facilitated by using Pseudomonas sp. strain ADP, a bacterium that can rapidly mineralize these two herbicides, but none of their metabolites.

\section{MATERIALS AND METHODS}

Soil, Organic Amendment, and Chemicals. Two different sandy soils were used in this study, one from Sevilla, Spain (SP-U), and another from Becker, Minnesota (MN-U). The same soils were also amended with alperujo (SP-A and MN-A, respectively), the organic solid waste from the two-phase, olive oil extraction process. The SP-U soil was taken from the $0-15 \mathrm{~cm}$ depth from an olive grove located in Coria del Rio (Sevilla, Spain), air-dried, and sieved with a 2-mm mesh screen. Soil properties were as follows: $\mathrm{pH} 8.4,0.36 \%$ organic carbon (OC), $20 \%$ clay, $9 \%$ silt, and $71 \%$ sand. The soil was classified as Typic Rhodoxeralf. The MN-U soil, which was classified as a Hubbard loamy sand, had a pH of 5.8, and contained $86.0 \%$ sand, $6.0 \%$ clay, and $1.5 \%$ OC. Neither soil had a history of triazine application in the previous $7-10$ yrs. The soils were amended in the laboratory with alperujo to $2.78 \%$ OC in SP-A and $4.38 \%$ OC in MN-A. The properties of the alperujo used were: $\mathrm{pH} 5.8,93.2 \% \mathrm{OM}, 25 \mathrm{~g} \mathrm{~kg}^{-1}$ dissolved organic carbon (DOC), and a $\mathrm{C}: \mathrm{N}$ ratio of 18.3 .

Terbuthylazine ( $N^{2}$-tert-butyl-6-chloro- $N^{4}$-ethyl-1,3,5-triazine-2,4diamine) (99\% purity) was purchased from Riedel-de Haën (Seelze, Germany), and UL-ring- ${ }^{14} \mathrm{C}$ - labeled terbuthylazine $\left(1.99 \mathrm{MBq} \mathrm{mg}^{-1}\right.$ specific activity; $94.3 \%$ radiochemical activity) was kindly supplied by Syngenta (Basel, Switzerland). Atrazine (6-chloro- $N^{2}$-ethyl- $N^{4}$ isopropyl-1,3,5-triazine-2,4-diamine) was purchased from Chem Service (West Chester, PA) (98\% purity), and UL-ring- ${ }^{14} \mathrm{C}$-labeled atrazine (1.63 $\mathrm{Mbq} \mathrm{mg}^{-1}$ specific activity; $98.7 \%$ radiochemical purity) was purchased from Sigma-Aldrich (St. Louis, MO).

${ }^{14} \mathrm{C}$-Herbicide Sorption in Aged Soil Studies by Analysis of Extractable Herbicides. Unamended and alperujo-amended soils (10 g dry weight) were individually weighed into triplicate glass tubes, and methanolic terbuthylazine $(0.6 \mathrm{~mL})$ or atrazine $(1.1 \mathrm{~mL})$ solutions were added to each soil to a final triazine concentration of $1 \mu \mathrm{g} \mathrm{g}^{-1}$ and $168.2 \mathrm{~Bq} \mathrm{~g}^{-1}$. After evaporation of the methanol $(\sim 1 \mathrm{~h})$, distilled water was added to obtain a soil moisture content of $40 \%$ of the water-holding capacity. Glass wool was placed on the soil surface, and a vial containing $1 \mathrm{~mL}$ of $0.5 \mathrm{~N} \mathrm{NaOH}$ was placed in the tube to trap ${ }^{14} \mathrm{CO}_{2}$ resulting from the mineralization of ${ }^{14} \mathrm{C}$-terbuthylazine or ${ }^{14} \mathrm{C}$-atrazine. Tubes were stoppered, and soils were incubated in the dark at $25 \pm 1{ }^{\circ} \mathrm{C}$ for 7,14 , and 28 days for terbuthylazine studies, and for 14 and 25 days for atrazine studies. The $\mathrm{NaOH}$ was replaced weekly, and a $1 \mathrm{~mL}$ aliquot was mixed with $6 \mathrm{~mL}$ of EcoLite scintillation cocktail. Radioactivity in vials was counted, for $5 \mathrm{~min}$, using a Tri-Carb 1500 Packard liquid scintillation analyzer. Vials were kept in the dark overnight prior to counting to reduce chemiluminescence.

At time 0 (immediately after solvent evaporation) and after each incubation period, soil samples were extracted by shaking with $20 \mathrm{~mL}$ of $0.01 \mathrm{~N} \mathrm{CaCl}_{2}$ for $20 \mathrm{~h}$ on a horizontal shaker, and centrifuged at $1500 \mathrm{~g}$ for $30 \mathrm{~min}$. The supernatant volume was measured, and a $1 \mathrm{~mL}$ aliquot was mixed with $6 \mathrm{~mL}$ of EcoLite scintillation cocktail. Radioactivity was measured as described above. The remaining aqueous supernatant was kept at $4{ }^{\circ} \mathrm{C}$ until it was extracted with dichloromethane (DCM) for analysis of parent herbicide.

The soil was subsequently extracted with $20 \mathrm{~mL}$ of methanol:water (80:20, v:v), by shaking for $20 \mathrm{~h}$ in a horizontal shaker. After the sample was centrifuged at $1500 \mathrm{~g}$ for $30 \mathrm{~min}$, the supernatant was removed, a $1 \mathrm{~mL}$ aliquot was mixed with $6 \mathrm{~mL}$ of EcoLite scintillation cocktail, and radioactivity was determined as described above. The remaining aliquot was analyzed by HPLC to quantify the organic-extractable parent herbicide as described below. The extracted soils were then frozen at $-25{ }^{\circ} \mathrm{C}$ until they were later combusted to determine unextractable (bound) ${ }^{14} \mathrm{C}$.

The methanol was removed from the aqueous methanol supernatant using a Zymark Turbo Vap II evaporator at $35^{\circ} \mathrm{C}$. The water extracts remaining and the supernatants of the $0.01 \mathrm{~N} \mathrm{CaCl}_{2}$ extractions were each extracted twice with DCM (1:4 DCM:aqueous, v:v). The two DCM 
solutions from the $0.01 \mathrm{~N} \mathrm{CaCl}_{2}$ extractions were combined and evaporated using $\mathrm{N}_{2}$ gas, just to dryness, in a water bath at $35^{\circ} \mathrm{C}$. The two DCM solutions from the aqueous methanol supernatants were combined and similarly processed. The residues were redissolved with $1 \mathrm{~mL}$ of acetonitrile (ACN):water (40:60, v:v) and analyzed by high performance liquid chromatography (HPLC), using a 1090 HewlettPackard high performance liquid chromatograph and a Waters Spherisorb C8 $5 \mu \mathrm{m} 150 \mathrm{~mm} \times 4.6 \mathrm{~mm}$ i.d. column. The mobile phase, at a flow rate of $1 \mathrm{~mL} \mathrm{~min}{ }^{-1}$, was a gradient of $\mathrm{ACN}$ and milli Q water, starting at $40 \%$ of $\mathrm{ACN}$ until minute 15 and changing to $70 \% \mathrm{ACN}$ at minute 22. The injection volume was $50 \mu \mathrm{L}$.

For terbuthylazine, fractions were collected from time 0 to $10 \mathrm{~min}$, and then at each minute until minute 16, and another fraction from 16 to $22 \mathrm{~min}$. For atrazine, fractions were collected from time 0 to $5 \mathrm{~min}$, then each minute until $10 \mathrm{~min}$ and from 10 to $15 \mathrm{~min}$. One milliliter aliquots of the fraction corresponding to terbuthylazine and atrazine were mixed with $6 \mathrm{~mL}$ of EcoLite scintillation cocktail, and radioactivity was measured in the LSC to calculate the amount of herbicide in supernatants. One milliliter aliquots of the remaining fractions were also counted to enable calculation of the percentage of parent herbicide in the extracted ${ }^{14} \mathrm{C}$. No standards were available to determine individual ${ }^{14} \mathrm{C}$-metabolites in the solutions.

Sorption coefficients, $K_{\mathrm{d}}$ values, were calculated assuming that the methanol-extractable herbicide was the amount of herbicide sorbed by soil $\left(C_{\mathrm{s}}\right)$ and that the water-extractable pesticide was the equilibrium concentration of herbicide in solution $\left(C_{\mathrm{e}}\right)$ as in the batch equilibration method: $K_{\mathrm{d}}=C_{\mathrm{s}} / C_{\mathrm{e}}$. The $K_{\mathrm{oc}}$ values were calculated as $\left(K_{\mathrm{d}} / \mathrm{OC}\right) \times$ 100.

Quantification of Unextractable (Bound) ${ }^{14}$ C-Residues. Before nonextractable $\left[{ }^{14} \mathrm{C}\right]$ terbuthylazine or $\left[{ }^{14} \mathrm{C}\right]$ atrazine was determined, soil moisture was measured in the previous extracted soils. Soil samples, $0.33 \mathrm{~g}$ (dry weight) of each sample in triplicate, were combusted by using a Packard 307 sample oxidizer. The ${ }^{14} \mathrm{CO}_{2}$ released was trapped in Carbo-Sorb E mixed with Permafluor V, and the ${ }^{14} \mathrm{C}$ was quantified by liquid scintillation counting (LSC) as described above.

${ }^{14} \mathrm{C}$-Triazine Bioavailability to Pseudomonas in Aged Soil Studies. In parallel studies, an experiment was conducted to determine herbicide bioavailability using Pseudomonas sp. strain ADP, an atrazine degrading bacterium. Alperujo-amended and unamended soils (10 g dry weight) were individually placed in tubes and treated with $0.6 \mathrm{~mL}$ of ${ }^{14} \mathrm{C}$-labeled terbuthylazine or $1.1 \mathrm{~mL}$ of ${ }^{14} \mathrm{C}$-labeled atrazine solutions in the same way as was done in the sorption studies. At time 0 , and after each incubation period (7, 14, and $28 \mathrm{~d}$ for terbuthylazine in SP soil and 9, 17, and $26 \mathrm{~d}$ for atrazine in MN soil, and 10 and $26 \mathrm{~d}$ for atrazine in SP soil), soils were inoculated with a 1 or $2 \mathrm{~mL}$ suspension of Pseudomonas sp. strain ADP (final inoculum density $1 \times 10^{8}$ or $2 \times 10^{8}$ microorganisms $\mathrm{g}^{-1}$ soil, respectively), and mixed thoroughly. Methods for growing and maintaining the organism have been previously reported $(24,25)$. Glass wool was placed on the soil surface, and a vial containing 1 $\mathrm{mL}$ of $0.5 \mathrm{~N} \mathrm{NaOH}$ was placed in the tube to trap ${ }^{14} \mathrm{CO}_{2}$ resulting from the mineralization of ${ }^{14} \mathrm{C}$-terbuthylazine or ${ }^{14} \mathrm{C}$-atrazine. The $\mathrm{NaOH}$ in vials was replaced 24,48 , and $72 \mathrm{~h}$ after inoculation. A 1 $\mathrm{mL}$ aliquot of the $\mathrm{NaOH}$ solution was mixed with $6 \mathrm{~mL}$ of EcoLite scintillation cocktail, vials were kept in dark overnight, and radioactivity was measured using LSC as described above.

\section{RESULTS AND DISCUSSION}

To characterize the availability of aged terbuthylazine and atrazine residues for transport in alperujo-amended and unamended soils, the partitioning of terbuthylazine and atrazine between aqueous extractable, solvent extractable, and bound residues, as a function of time, was determined. The bacterium Pseudomonas sp. strain ADP was also used to determine the bioavailability of aged terbuthylazine and atrazine residues in unamended and alperujo-amended soils. To facilitate these experiments, ${ }^{14} \mathrm{C}$-labeled triazine herbicides were used.

The mass balance of applied ${ }^{14} \mathrm{C}$-triazines in the tested soils was excellent. The mass balance of ${ }^{14} \mathrm{C}$ from ${ }^{14} \mathrm{C}$-terbuthylazine
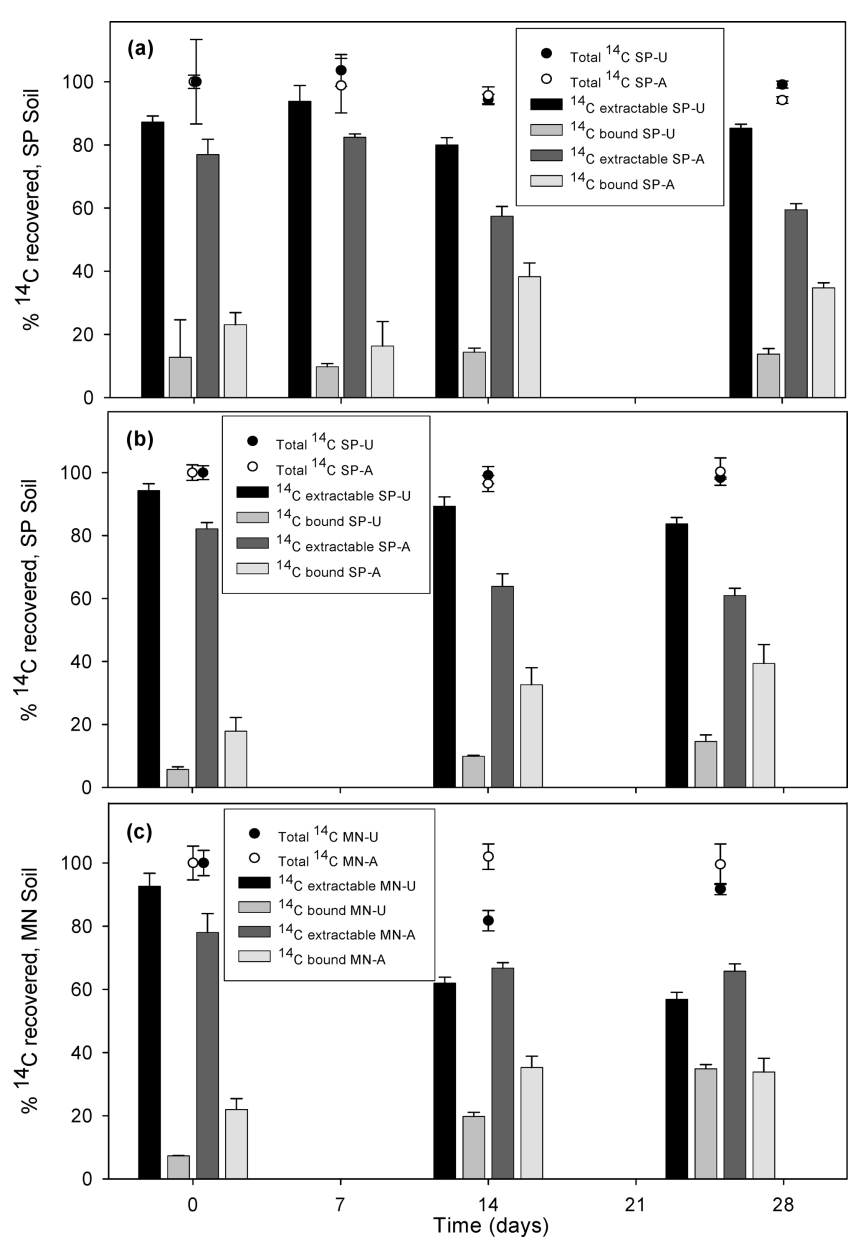

Figure 1. Mass balance of extractable and bound ${ }^{14} \mathrm{C}$ in unamended (U) and amended (A) soils: (a) from ${ }^{14} \mathrm{C}$-terbuthylazine in SP soil; (b) from ${ }^{14} \mathrm{C}$-atrazine in SP soil; (c) from ${ }^{14} \mathrm{C}$-atrazine in MN soil.

in SP-U and SP-A, averaged over all sampling times, was $99.3 \%$ and $97.2 \%$, respectively (Figure 1a). Aging did not significantly affect the extractability of the terbuthylazine ${ }^{14} \mathrm{C}$-residues from $\mathrm{SP}-\mathrm{U}$; the ratio of total extractable to unextractable ${ }^{14} \mathrm{C}$ was about the same for the four sampling times, with $>80 \%$ extractable and $\leq 15 \%$ unextractable (bound) ${ }^{14} \mathrm{C}$ at all sampling times. In contrast, terbuthylazine ${ }^{14} \mathrm{C}$-residues became increasingly bound with time in the SP-A soil; the ratio of extractable to unextractable residues decreased from 3.3 to 1.7 during the incubation period. Total extractable terbuthylazine ${ }^{14} \mathrm{C}$ residues decreased from $76.9 \%$ to $59.5 \%$ during the 4 wk incubation period, while ${ }^{14} \mathrm{C}$ unextractable residues increased with time from $23.1 \%$ at time 0 to $34.8 \%$ after 4 wks of incubation.

The results for atrazine in SP soil were similar to those for terbuthylazine. The average mass balance of ${ }^{14} \mathrm{C}$ from ${ }^{14} \mathrm{C}$ atrazine in SP-U and SP-A was $99.2 \%$ and $98.9 \%$, respectively (Figure 1b). The percentage of total atrazine ${ }^{14} \mathrm{C}$ residues extracted decreased with aging in both unamended and amended SP soil, from $94.3 \%$ to $83.7 \%$ in SP-U after $26 \mathrm{~d}$, and from $82.2 \%$ to $60.9 \%$ during the same period in the SP-A soil, respectively. Bound atrazine ${ }^{14} \mathrm{C}$ residues increased with aging, from $5.7 \%$ to $14.6 \%$ in SP-U and from $17.8 \%$ to $39.4 \%$ in SP-A after nearly $4 \mathrm{wks}$. The ratio of total extractable to unextractable ${ }^{14} \mathrm{C}$ decreased in both unamended and amended soils, from 17 to 6 after the $26 \mathrm{~d}$ incubation period in SP-U, and from 5 to 2 in the SP-A soil.

The average amount of ${ }^{14} \mathrm{C}$ from ${ }^{14} \mathrm{C}$-atrazine recovered, averaged over all sampling times, for $\mathrm{MN}-\mathrm{U}$ and $\mathrm{MN}-\mathrm{A}$ was $91.2 \%$ and $100.5 \%$, respectively (Figure 1c). The ratio between 

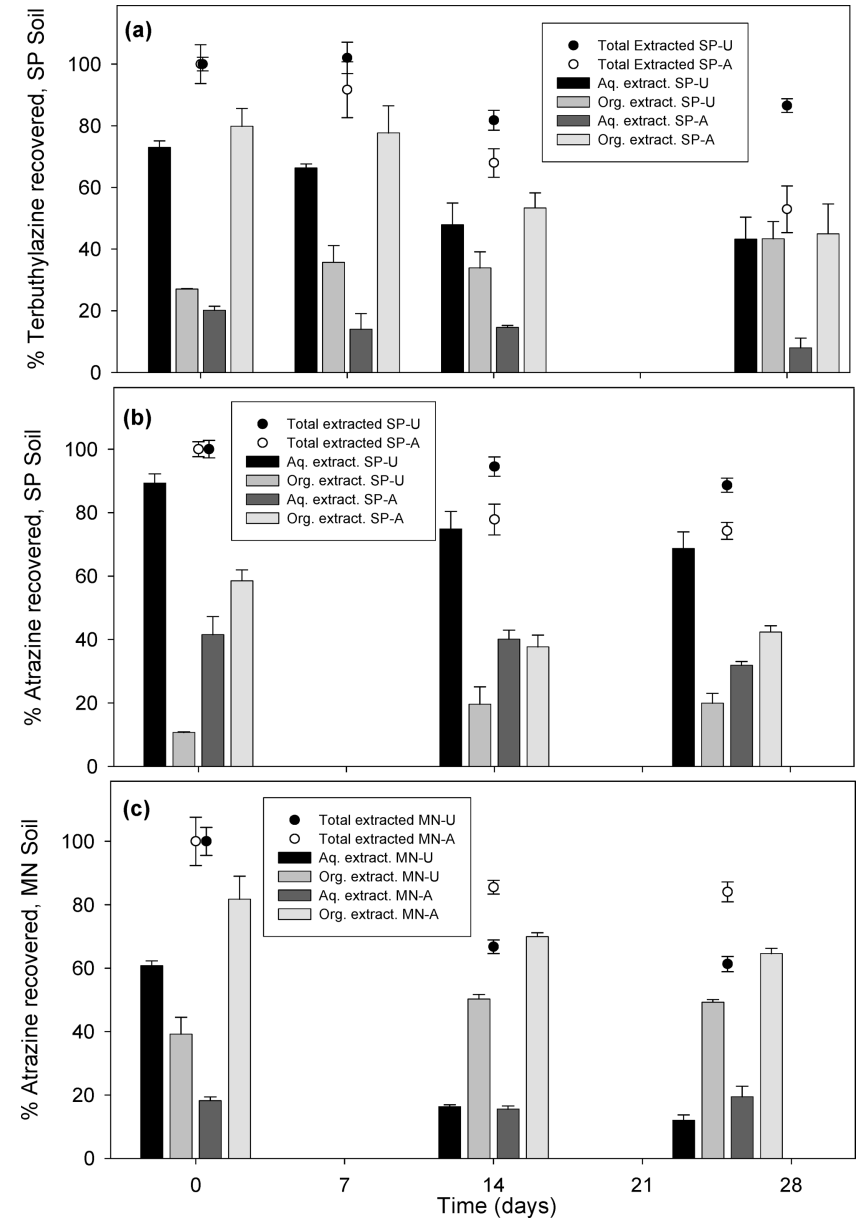

Figure 2. Aqueous-extractable and organic-extractable herbicide in unamended (U) and amended (A) soils: (a) terbuthylazine in SP soil; (b) atrazine in SP soil; (c) atrazine in MN soil.

extractable and unextractable ${ }^{14} \mathrm{C}$-atrazine residues decreased from 13 to 2 in the MN-U soil after the $26 \mathrm{~d}$ incubation period; however, the ratio only slightly decreased (3.5 to 1.9) in the MN-A soil. Extractable ${ }^{14} \mathrm{C}$ residues in the $\mathrm{MN}-\mathrm{U}$ decreased with aging, from $92.7 \%$ to $56.9 \%$ after $26 \mathrm{~d}$, and from $78.0 \%$ to $65.8 \%$ in the $\mathrm{MN}-\mathrm{A}$ soil during the same time period. Bound atrazine ${ }^{14} \mathrm{C}$ residues increased in both soils, from $7.3 \%$ to $34.9 \%$ in $\mathrm{MN}-\mathrm{U}$ and from $22.0 \%$ to $33.8 \%$ in MN-A during the $26 \mathrm{~d}$ incubation period.

The amount of terbuthylazine and atrazine in the extractable ${ }^{14} \mathrm{C}$ residues was determined by HPLC. Less terbuthylazine was recovered from the amended SP soil after $4 \mathrm{wks}$ (50\% of applied) as compared to unamended soil (90\% of applied) (Figure 2a). After $26 \mathrm{~d}$ of incubation, atrazine recovery also was lower in amended SP soil (75\% of applied recovered) as compared to that in unamended soil $(90 \%$ recovered) (Figure 2b). The recovery of atrazine from $\mathrm{MN}$ soil was slightly lower as compared to the SP soil; after $26 \mathrm{~d}$ $60 \%$ and $85 \%$ of applied atrazine was recovered from unamended and amended MN soils, respectively (Figure 2c). The decrease in recovery of both herbicides may be attributed to microbial degradation during the incubation period. Although there was no attempt to determine metabolites in this study, we did determine that ${ }^{14} \mathrm{C}$-terbuthylazine and ${ }^{14} \mathrm{C}$ atrazine mineralization by soil microorganisms was $<0.1 \%$ of the initially applied herbicides in all tested amended and unamended soils (data not shown). The lack of mineralization of triazines in numerous soils has been shown by others. For example, insignificant amounts of atrazine were reported to be mineralized in five of six soils (three unamended soils and three amended with treated wastewater), and the percentage of atrazine mineralized in those soils only slightly increased with increasing aging time (26).

The decrease in recovery of parent herbicide may also be due to an increase in the amounts of unextractable herbicides bound to soil components due to a soil aging effect, similar to that reported by Gevao et al. (27). Bound pesticide residues tend to lose their biological activity with longer residence times in soil, becoming more resistant to degradation and extraction. Numerous studies have reported that the formation of bound residues by organic chemicals is enhanced after amendment of soils with organic matter $(16,28)$. The large amount of total ${ }^{14} \mathrm{C}$ recovered during the $4 \mathrm{wk}$ incubation period (Figure 1), however, suggests that microbial degradation of the herbicides, and formation of metabolites, is the likely cause of the decreased recovery of parent herbicide in our studies.

Since $60-90 \%$ and $50-85 \%$ of the applied herbicides remained in unamended and alperujo-amended soils after aging, the quantity of the remaining herbicides available for transport and degradation was determined at selected times during the incubation. To do this, the herbicides were sequentially extracted with $0.01 \mathrm{~N} \mathrm{CaCl}_{2}$, followed by extractions with aqueous methanol. The amounts of aqueous extractable (readily available) herbicides decreased with incubation time in unamended SP and MN soils, while the amounts of organic solvent extractable (sorbed herbicide) increased (Figure 2). Aqueous extractable terbuthylazine in SP-U soil decreased from $73 \%$ of initially applied to $43 \%$ after 4 wks, whereas the amount extracted with organic solvent increased from $27 \%$ to $43 \%$ (Figure 2a). Aqueous extractable atrazine also decreased after $26 \mathrm{~d}$ of incubation (from $89.3 \%$ of initially applied to $68.7 \%$ in SP-U, and from $60.8 \%$ to $12.1 \%$ in MN-U) (Figure $2 \mathbf{b}, \mathbf{c}$ ). The amount of solvent extractable atrazine increased by $10 \%$ in both SP-U and $\mathrm{MN}-\mathrm{U}$ after the $25 \mathrm{~d}$ incubation period (from $10.7 \%$ to $20.0 \%$, SP-U; from $39.2 \%$ to $49.3 \%$ in MN-U) (Figure 2b,c).

In contrast to the unamended soils, both aqueous and organic extractable terbuthylazine decreased with time in amended SP soil (from $20 \%$ to $8.0 \%$, and from $80 \%$ to $45 \%$, respectively) (Figure 2a). The amounts of both aqueous and organic extractable atrazine also decreased with time, by $10-16 \%$ in SP-A (from $41.5 \%$ to $31.9 \%$ for aqueous extractable), and from $58.5 \%$ to $42.4 \%$ for solvent extractable (Figure 2b). In contrast, aqueous extractable atrazine in $\mathrm{MN}-\mathrm{A}$ did not vary significantly during the $25 \mathrm{~d}$ incubation period (from 18.2\% to 19.4\%), whereas organic extractable decreased with time (from $81.8 \%$ to $64.6 \%$ ) (Figure 2c).

The availability of herbicides for transport has been traditionally characterized by determination of aqueous extractable herbicide or by calculation of sorption coefficients, $K_{\mathrm{d}}$ values, or Freundlich coefficients, $K_{\mathrm{f}}$ and $1 / n_{\mathrm{f}}$ values. The $K_{\mathrm{d}}$ values (Table 1) were calculated using the quantity of herbicides measured in the aqueous (solution phase) and in organic extracts (sorbed phase) at each incubation time. The terbuthylazine sorption $K_{\mathrm{d}}$, averaged over the 4 wk incubation period, was higher by a factor of 8 in the amended SP soil, as compared to unamended SP soil. In amended soils (SP-A and MN-A), the $K_{\mathrm{d}}$ values for atrazine were also higher as compared to the $K_{\mathrm{d}}$ values in the unamended soils, except for the MN soil after the $25 \mathrm{~d}$ incubation period. The greater sorption in amended soils was attributed to the higher content of OC $(2.78 \%$ OC in SPA, vs $0.36 \%$ OC in SP-U; and $4.36 \%$ OC in MN-A, vs $1.50 \%$ 
Table 1. $K_{d}$ and $K_{o c}$ Values Calculated for Unamended (U) and Amended (A) Spanish (SP) and Minnesota (MN) Soils after Different Aging Times

incubation time $(d)$

\begin{tabular}{|c|c|c|c|c|c|c|c|c|c|}
\hline \multirow[b]{3}{*}{ triazine } & \multirow[b]{3}{*}{ soil } & \multirow{2}{*}{\multicolumn{4}{|c|}{$K_{\mathrm{d}}\left(\mathrm{mL} \mathrm{g}^{-1}\right)$}} & \multirow{2}{*}{\multicolumn{4}{|c|}{$K_{o c}\left(\mathrm{~mL} \mathrm{~g}^{-1}\right)$}} \\
\hline & & & & & & & & & \\
\hline & & 0 & 7 & 14 & $28^{a}$ & 0 & 7 & 14 & $28^{a}$ \\
\hline \multirow[t]{2}{*}{ terbuthylazine } & SP-U & $1.0 \pm 0.0$ & $1.4 \pm 0.3$ & $2.0 \pm 0.6$ & $2.8 \pm 0.8$ & $278 \pm 7$ & $389 \pm 72$ & $556 \pm 157$ & $778 \pm 216$ \\
\hline & SP-A & $10.7 \pm 0.9$ & $12.1 \pm 2.0$ & $10.0 \pm 1.2$ & $22.2 \pm 0.5$ & $385 \pm 32$ & $435 \pm 71$ & $360 \pm 43$ & $799 \pm 17$ \\
\hline \multirow{3}{*}{ atrazine } & SP-A & $3.9 \pm 0.7$ & $2.6 \pm 0.3$ & & $3.6 \pm 0.2$ & $140 \pm 25$ & $94 \pm 11$ & & $129 \pm 6$ \\
\hline & MN-U & $1.7 \pm 0.3$ & $7.9 \pm 0.2$ & & $10.7 \pm 1.4$ & $113 \pm 18$ & $527 \pm 11$ & & $713 \pm 93$ \\
\hline & MN-A & $11.6 \pm 1.1$ & $11.7 \pm 0.6$ & & $8.8 \pm 1.5$ & $265 \pm 26$ & $266 \pm 14$ & & $201 \pm 35$ \\
\hline
\end{tabular}

${ }^{a}$ Atrazine incubation was $25 \mathrm{~d}$.

OC in MN-U), as has been widely reported by many authors (29-32). Delgado-Moreno et al. (22) also observed an increase in $K_{\mathrm{f}}$ values for four triazine herbicides, including terbuthylazine, in soil freshly amended with olive-mill waste as compared to unamended soil. However, if the soil was preincubated with the organic amendment for 1-3 months, there was no difference in sorption for amended and unamended soils (22).

Aging, or residence time, of the herbicides in soil, caused an increase, with time, in the apparent $K_{\mathrm{d}}$ and $K_{\mathrm{oc}}$ values for terbuthylazine in both unamended and amended SP soils. In SP-U, the $K_{\mathrm{d}}$ increased by a factor of 2.8 after 4 wk of incubation and by a factor of 2.1 in the SP-A soil during the same period of time (Table 1). Atrazine $K_{\mathrm{d}}$ and $K_{\mathrm{oc}}$ values also increased with aging time in the unamended SP-U soil by a factor of 3.0, and by a factor of 6.5 for the $\mathrm{MN}-\mathrm{U}$ soil. However, in the amended soils (SP-A and MN-A), the atrazine $K_{\mathrm{d}}$ and $K_{\mathrm{oc}}$ values did not change significantly during the incubation period. Similar results were reported by Johannesen and Aamand (33) who calculated $K_{\mathrm{d}}$ in aged soils from the pore-water content of ${ }^{14} \mathrm{C}$ and found an increase in sorption of atrazine and terbuthylazine in unamended soil with aging time. Similar increases in sorption with incubation time have also been observed for a variety of classes of herbicides, including the sulfonylaminocarbonyltriazolinone herbicides (34). In contrast, Menasseri et al. (35) did not observe an increase in sorption of dicamba in either amended or unamended soil with increased aging time.

Sorption is one of the main processes that affects the fate of pesticides in soil and water (36), and sorption-desorption interactions of pesticides with soil determine the availability of these organic compounds for plant uptake, transport, and microbial degradation in soil (37). Equilibrium sorption estimates ( $K_{\mathrm{d}}$ and $K_{\mathrm{oc}}$ values) can be used to predict the mobility of pesticides in soil $(38,39)$.

Transport models typically use $K_{\mathrm{d}}$ or $K_{\mathrm{oc}}$ values to describe pesticide retention by soil (40). The accuracy of the sorption estimates can be more important than the choice of transport model in correctly simulating pesticide leaching (40), emphasizing the need for evaluating pesticide sorption in aged soils. Aging effects on sorption can also impact mobility classifications of pesticides. For instance, mobility classification based on a unitless retardation factor (RF) (41), which in turn is a function of $K_{\mathrm{d}}$, would change from moderately mobile to moderately immobile for terbuthylazine and atrazine in the unamended soils. In contrast, aging would not have an effect on amended MN soil.

Pseudomonas sp. strain ADP, a triazine mineralizing bacterium (24), has previously been used to determine the bioavailability of selected triazines in soil $(42,43)$. In freshly treated soil, atrazine and terbuthylazine mineralization by Pseudomonas sp. strain ADP has been shown to be inversely related to soil sorption (i.e., less mineralization was seen with increased sorption) (42). Atrazine bioavailability has been reported to decrease in aged soil, as evidenced by decreased mineralization of atrazine by Pseudomonas ADP in soils aged for different lengths of time soil prior to inoculation with Pseudomonas ADP (43). In the same study with a subsurface soil, atrazine mineralization was significantly reduced when the aging time exceeded $1 \mathrm{~d}$, whereas no differences were observed between mineralization rates of samples aged 7-30 d. In a similar study done using a surface soil, atrazine mineralization decreased as a function of increased aging time; however, no effect of aging on atrazine mineralization was observed for an aquifer sediment (33).

In the above-mentioned studies on aging effects on atrazine mineralization, however, there were no independent measurements of the amounts of atrazine present in the aged soils. Since Pseudomonas sp. strain ADP has been shown to be able to mineralize, within hours, the same amount of atrazine and simazine in aged soils that was extractable from the same aged soils using aqueous methanol $(25,44)$, it may be possible that the reported decrease in mineralization of ${ }^{14} \mathrm{C}$ atrazine by Pseudomonas ADP $(33,42,43)$ was due to decreased amounts of atrazine present with aging, as opposed to decreased availability of the aged residues to the degrading microorganism. Although there are studies on bioavailability of pesticides in soils of different organic matter content, we are aware of no research that has used a specific degrading bacterium to study the effects of organic amendments, such as alperujo, on bioavailability of aged atrazine and terbuthyalzine residues.

To examine the influence of organic amendments on bioavailability of aged pesticide residues in more detail, Pseudomonas sp. strain ADP was added to aged, alperujo-amended, and unamended soils, and ${ }^{14} \mathrm{C}$ mineralization was followed over time. In unamended SP soil (SP-U), the amount of ${ }^{14} \mathrm{C}$ terbuthylazine mineralized by Pseudomonas ADP increased from $6 \%$ to $11 \%$ of applied chemical at the end of a $28 \mathrm{~d}$ incubation period (Table 2). Even though Pseudomonas sp. strain ADP has been shown to be less efficient at mineralizing terbuthylazine as compared to atrazine $(33,42)$, the amount of ${ }^{14} \mathrm{C}$-terbuthylazine mineralized by Pseudomonas sp. strain ADP was less than expected considering the amount of water extractable terbuthylazine ( $>70 \%$ of applied terbuthylazine) (Figure 2a). In the case of ${ }^{14} \mathrm{C}$-atrazine, the total amount of herbicide mineralized by the bacterium was also lower than expected at time 0 , particularly because $>90 \%$ of the atrazine was aqueous extractable. Increasing the inoculation density of Pseudomonas sp. strain ADP in the SP-U soil from $1 \times 10^{8}$ to $2 \times 10^{8}$ organisms $\mathrm{g}^{-1}$ nearly doubled the amount of atrazine mineralized at time 0 , from $5 \%$ to $8 \%$ of applied. The average amount of atrazine mineralized in unamended MN soil (MN$\mathrm{U})$ by the lower density inoculum during the $17 \mathrm{~d}$ incubation period (23\% of applied) was slightly higher than when MN-U 
Table 2. ${ }^{14} \mathrm{C}$ Herbicide Mineralized by Pseudomonas sp. Strain ADP in Unamended (U) and Amended (A) Spanish (SP) and Minnesota (MN) Soils during a 28 day Incubation

\begin{tabular}{|c|c|c|c|c|c|c|}
\hline \multirow[b]{2}{*}{ triazine } & \multirow[b]{2}{*}{ soil } & \multirow[b]{2}{*}{ inoculum density (organisms $\mathrm{g}^{-1}$ ) } & \multicolumn{4}{|c|}{ herbicide mineralized during incubation (\% of applied) } \\
\hline & & & $T=0 \mathrm{~d}$ & $T=7-10 \mathrm{~d}^{a}$ & $T=14-17 \mathrm{~d}^{b}$ & $T=26-28 d^{c}$ \\
\hline \multirow[t]{2}{*}{ terbuthylazine } & SP-U & $1 \times 10^{8}$ & $5.7 \pm 1.6$ & $<1$ & $5.9 \pm 0.5$ & $11.1 \pm 3.1$ \\
\hline & SP-A & $1 \times 10^{8}$ & $<1$ & $<1$ & $1.0 \pm 0.5$ & $<1$ \\
\hline \multirow[t]{8}{*}{ atrazine } & SP-U & $1 \times 10^{8}$ & $5.3 \pm 1.4$ & $34.4 \pm 11.2$ & & \\
\hline & SP-U & $2 \times 10^{8}$ & $8.2 \pm 1.6$ & $12.0 \pm 2.5$ & & $30.8 \pm 11.3$ \\
\hline & SP-A & $1 \times 10^{8}$ & $<1$ & $1.7 \pm 0.9$ & & \\
\hline & SP-A & $2 \times 10^{8}$ & $<1$ & $3.5 \pm 1.4$ & & $25.2 \pm 9.8$ \\
\hline & MN-U & $1 \times 10^{8}$ & $13.3 \pm 0.3$ & $29.0 \pm 12.6$ & $23.1 \pm 2.6$ & \\
\hline & MN-U & $2 \times 10^{8}$ & $18.3 \pm 5.1$ & & $19.0 \pm 11.8$ & $15.4 \pm 5.0$ \\
\hline & MN-A & $1 \times 10^{8}$ & $<1$ & $<1$ & $<1$ & \\
\hline & MN-A & $2 \times 10^{8}$ & $<1$ & & $<1$ & $<1$ \\
\hline
\end{tabular}

${ }^{a} T=7 \mathrm{~d}$ terbuthylazine SP, $T=10 \mathrm{~d}$ atrazine SP, $T=9 \mathrm{~d}$ atrazine MN. ${ }^{b} T=14 \mathrm{~d}$ terbuthylazine, $T=17 \mathrm{~d}$ atrazine. ${ }^{c} T=28 \mathrm{~d}$ terbuthyalzine, $T=26 \mathrm{~d}$ atrazine.

soil was inoculated with twice as many microorganisms and incubated for $26 \mathrm{~d}$ (15\% of applied).

The amount of atrazine mineralized in SP-U at time 0 was also low in comparison with other studies of atrazine and simazine mineralization by Pseudomonas sp. strain ADP, but increased to comparable levels as has been previously reported by the end of the incubation period $(25,33,43,44)$. An increase in atrazine mineralization was observed in $\mathrm{MN}-\mathrm{U}$ soil with incubation. Jacobsen et al. (42) also observed less mineralization of terbuthylazine as compared to atrazine; in both cases, the amount of herbicide mineralized by the bacteria increased at the end of the aging period.

The amount of labeled herbicide mineralized by Pseudomonas sp. strain ADP in alperujo-amended soils was much less than that seen in the unamended soils, $<1 \%$ of applied at every aging time, except for atrazine in SP-A soil after 10 or $26 \mathrm{~d}$ incubation. These results indicate that olive mill waste used as organic amendment reduces either bioavailability or degradation of terbuthylazine and atrazine in soil. Masaphy and Mandelbaum (26) reported a significant decrease in atrazine mineralization rates in soils irrigated with treated wastewater as compared to the soils not irrigated. They attributed this decrease in mineralization to a combination of factors, the increase in sorption and complexation of atrazine with the $\mathrm{OM}$ in the soil with aging, and the increase in $\mathrm{N}$ of soil by the wastewater irrigation.

The low rate of triazine mineralization by Pseudomonas sp. strain ADP in these studies may be due to the microorganism's use of inorganic sources of $\mathrm{N}$ preferentially over herbicide-derived $\mathrm{N}$, thereby reducing triazine degradation. Laboratory studies have previously shown that inorganic nitrogen inhibits the ability of Pseudomonas ADP to degrade atrazine (45). It is possible that once the inorganic sources of $\mathrm{N}$ were depleted by microbial activity during the incubation in the unamended soils, particularly in SP soil, the Pseudomonas sp. strain ADP then used the triazines as a $\mathrm{N}$ source. It is suggested that in amended soil, alternate sources of $\mathrm{N}$ (alperujo $\mathrm{C}: \mathrm{N}$ ratio was relatively high, 18.3) were not depleted during the incubation, resulting in very little triazine mineralization $(<1 \%$ of applied triazine). However, the reported relationship between available $\mathrm{N}$ and atrazine mineralization is contradictory. Shapir et al. (46) found that atrazine mineralization activity of Pseudomonas sp. strain ADP was not negatively influenced by the addition of wastewater and sludge as amendments.

It appears that bioavailability of triazines in aged soil is a complex process that may be difficult to characterize. While Barriuso et al. (25) reported a correlation between the amounts of ${ }^{14} \mathrm{C}$-residues in water and organic extracts and bioavailable residues, and proposed that this may help to determine the bioavailability of other triazines, we could not use this correlation in our studies due to the low mineralization of herbicide by Pseudomonas sp. strain ADP in comparison with the amounts of extractable ${ }^{14} \mathrm{C}$. Jacobsen et al. (42), using a two compartment model on terbuthylazine mineralization and sorption data, suggested that terbuthylazine mineralization in soil inoculated with Pseudomonas sp. strain ADP was initially controlled by the rate of mineralization by Pseudomonas sp. strain ADP, followed by the sorption of terbuthylazine. They further suggested that in soils with high biodegrading potential, sorption was the limiting parameter for terbuthylazine mineralization, whereas in soils with low biodegrading potential, the limiting parameter was the number of degrading microorganisms. However, the present research indicates that the $\mathrm{N}$ status of the soil may be equally of importance. More work is needed on the relationship between the availability of inorganic $\mathrm{N}$ in soil and triazine mineralization by Pseudomonas sp. strain ADP.

In conclusion, addition of alperujo, a solid olive-mill waste, as an organic amendment to sandy soils from Spain and Minnesota resulted in reduced availability of two triazine herbicides, terbuthylazine and atrazine, as compared to unamended soils. In the Spanish soil, terbuthylazine sorption increased with aging in both amended and unamended soils. Aging/amendment interactions appear to be triazine dependent, and atrazine sorption increased with aging in both unamended Spanish and Minnesota soils. Although atrazine sorption was greater in alperujo-amended soils, as compared to unamended soils, aging had no effect on atrazine sorption in amended soils. Addition of alperujo decreased mineralization of both herbicides by Pseudomonas sp. strain ADP as compared to unamended soils. The mineralization of the herbicides in unamended soil increased with aging, possibly because of decreased readily available inorganic $\mathrm{N}$ in the soils during incubation.

\section{ACKNOWLEDGMENT}

We thank Andrea Bolks for her help with the sample oxidation and Brian Barber for his technical assistance.

\section{LITERATURE CITED}

(1) Leistra, M.; Boesten, J. J. T. I. Pesticide contamination of groundwater in Western-Europe. Agric. Ecosyst. Environ. 1989, 26, 369-389.

(2) Kolpin, D. W.; Barbash, J. E.; Gilliom, R. J. Occurrence of pesticides in shallow groundwater of the United States: Initial results from the National Water-Quality Assessment Program. Environ. Sci. Technol. 1998, 32, 558-566. 
(3) Barbash, J. E.; Thelin, G. P.; Kolpin, D. W.; Gilliom, R. J. Major herbicides in ground water. Results from the National WaterQuality Assessment. J. Environ. Qual. 2001, 30, 831-845.

(4) National Center for Food and Agriculture Policy (NCFAP). Pesticide use in U.S. crop production: 1997 National Summary Report. Giannesi, L. P.; Marcelli, M. B. November, 2000; www.ncfap.org/ncfap/nationalsummary 1997.pdf.

(5) Eurostat. Statistical books. The use of plant protection products in the European Union. Data 1992-2003. 2007 ed.

(6) The e-Pesticide Manual. A World Compendium, ver. 4.0, 14th ed.; Tomlin, C. D., Ed.; BCPC: Farham, U.K., 2006-2007.

(7) Cerrejeira, M. J.; Viana, P.; Batista, S.; Pereira, T.; Silva, E.; Valério, M. J.; Silva, A.; Ferreira, M.; Silva-Fernandes, A. M. Pesticides in Portuguese surface and ground waters. Water Res. 2003, 37, 1055-1063.

(8) Carabias-Martínez, R.; Rodríguez-Gonzalo, E.; Fernández-Laespada, M. E.; Calvo-Seronero, L.; Sánchez-San Román, F. J. Evolution over time of the agricultural pollution of waters in an area of Salamanca and Zamora (Spain). Water Res. 2003, 37, 928938.

(9) Guzzella, L.; Pozzoni, F.; Giuliano, G. Herbicide contamination of surficial groundwater in Northern Italy. Environ. Pollut. 2006, 142, 344-353.

(10) Barth, J. A. C.; Steidle, D.; Kuntz, D.; Gocht, T.; Mouvet, C.; von Tümpling, W.; Lobe, I.; Langenhoff, A.; Albrechtsen, H.-J.; Janniche, G. S.; Morasch, B.; Hunkeler, D.; Grathwohl, P. Deposition, persistence and turnover of pollutants. First results from the EU project AquaTerra for selected river basins and aquifers. Sci. Total Environ. 2007, 376, 40-50.

(11) Kolpin, D. W.; Thurman, E. M.; Goolsby, D. A. Occurrence of selected pesticides and their metabolites in near-surface aquifers of the midwestern United States. Environ. Sci. Technol. 1996, 30, 335-340.

(12) Lerch, R. N.; Blanchard, P. E.; Thurman, E. M. Contribution of hydroxylated atrazine degradation products to the total atrazine load in Midwestern streams. Environ. Sci. Technol. 1998, 32, 4048.

(13) Cox, L.; Celis, R.; Hermosin, M. C.; Becker, A.; Cornejo, J. Porosity and herbicide leaching in soils amended with olive-mill wastewater. Agric. Ecosyst. Environ. 1997, 65, 151-161.

(14) Si, Y.; Zhang, J.; Wang, S.; Zhang, L.; Zhou, D. Influence of organic amendment on the adsorption and leaching of ethametsulfuron-methyl in acidic soils in China. Geoderma 2006, 130, 66-76.

(15) Celis, R.; Barriuso, E.; Houot, S. Effect of liquid sewage sludge addition on atrazine sorption and desorption by soil. Chemosphere 1998, 37, 1091-1107.

(16) Houot, S.; Barriuso, E.; Bergheaud, V. Modification to atrazine degradation pathways in a loamy soil after addition of organic amendments. Soil Biol. Biochem. 1998, 30, 2147-2157.

(17) Majumdar, K.; Singh, N. Effect of soil amendments on sorption and mobility of metribuzin in soils. Chemosphere 2007, 66, 630637.

(18) Worrall, F.; Fernandez-Perez, M.; Johnson, A. C.; FloresCespedes, F.; Gonzalez-Pradas, E. Limitations on the role of incorporated organic matter in reducing pesticide leaching. $J$. Contam. Hydrol. 2001, 49, 241-262.

(19) Undabeytia, T.; Sanchez-Verdejo, T.; Morillo, E.; Maqueda, C. Effect of organic amendments on the retention and mobility of imazaquin in soils. J. Agric. Food Chem. 2004, 52, 44934500.

(20) Albarrán, A.; Celis, R.; Hermosín, M. C.; López-Piñeiro, A.; Ortega-Calvo, J. J.; Cornejo, J. Effects of solid olive-mill waste addition to soil on sorption, degradation and leaching of the herbicide simazine. Soil Use Manage. 2003, 19, 150-156.

(21) Albarrán, A.; Celis, R.; Hermosín, M. C.; López-Piñeiro, A.; Cornejo, J. Behaviour of simazine in soil amended with the final residue of the olive-oil extraction process. Chemosphere 2004, $54,717-724$.
(22) Delgado-Moreno, L.; Almendros, G.; Peña, A. Raw or incubated olive-mill wastes and its biotransformed products as agricultural soil amendments - effect on sorption-desorption of triazine herbicides. J. Agric. Food Chem. 2007, 55, 836-843.

(23) Farenhorst, A.; Reimer, M.; Londry, K.; Saiyed, I. 2,4-Dichlorophenoxy acetic acid mineralization in amended soil. J. Environ. Sci. Health, Part B 2006, 41, 509-522.

(24) Mandelbaum, R. T.; Allan, D. L.; Wackett, L. P. Isolation and characterization of a Pseudomonas sp that mineralizes the striazine herbicide atrazine. Appl. Environ. Microbiol. 1995, 61, 1451-1457.

(25) Barriuso, E.; Koskinen, W. C.; Sadowsky, M. J. Solvent extraction characterization of bioavailability of atrazine residues in Soils. $J$. Agric. Food Chem. 2004, 52, 6552-6556.

(26) Masaphy, S.; Mandelbaum, R. T. Atrazine mineralization in slurries from soils irrigated with treated waste water. Appl. Soil Ecol. 1997, 6, 283-291.

(27) Gevao, B.; Semple, K. T.; Jones, K. C. Bound pesticide residues in soils: a review. Environ. Pollut. 2000, 108, 3-14.

(28) Navarro, S.; Vela, N.; García, C.; Navarro, G. Persistence of simazine and terbuthylazine in a semirarid soil after organic amendment with urban sewage sludge. J. Agric. Food Chem. 2003, $51,7359-7365$.

(29) Cox, L.; Koskinen, W. C.; Yen, P. Y. Changes in sorption of imidacloprid with incubation time. Soil Sci. Soc. Am. J. 1998, 62, 342-347.

(30) Sánchez-Camazano, M.; Sánchez-Martín, M.; Delgado-Pascual, R. Adsorption and mobility of linuron in soils as influenced by soil properties, organic amendments, and surfactants. J. Agric. Food Chem. 2000, 48, 3018-3026.

(31) Said-Pullicino, D.; Gigliotti, G.; Vella, A. J. Environmetal fate of triasulfuron in soils amended with municipal waste compost. J. Environ. Qual. 2004, 33, 1743-1751.

(32) Dorado, J.; López-Fando, C.; Zancada, M. C.; Almendros, G. Sorption-desorption of alachlor and linuron in a semiarid soil as influenced by organic matter properties after 16 years of periodic inputs. J. Agric. Food Chem. 2005, 53, 5359-5365.

(33) Johannesen, H.; Aamand, J. Mineralization of aged atrazine, terbuthylazine, 2,4-D, and mecoprop in soil and aquifer sediment. Environ. Toxicol. Chem. 2003, 22, 722-729.

(34) Koskinen, W. C.; Rice, P. J.; Anhalt, J. A.; Sakaliene, O.; Moorman, T. B.; Arthur, E. L. Sorption-desorption of "aged" sulfonylaminocarbonyltriazolinone herbicides in soil. J. Agric. Food Chem. 2002, 50, 5368-5372.

(35) Menasseri, S.; Koskinen, W. C.; Yen, P. Y. Sorption of aged dicamba residues in soil. Pest Manage. Sci. 2004, 60, 297-304.

(36) Koskinen, W. C.; Harper, S. S. The Retention Process: Mechanisms. In Pesticides in the Soil Environment: Processes, Impacts and Modelling; Cheng, H. H., Ed.; ASSS: Madison, WI, 1990; Book Series, no. 2, pp 51-77.

(37) Koskinen, W. C.; Calderón, M. J.; Rice, P. J.; Cornejo, J. Sorptiondesorption of flucarbazone and propoxycarbazone and their benzenesulfonamide and triazolinone metabolites in two soils. Pest Manage. Sci. 2006, 62, 598-602.

(38) Wauchope, R. D.; Yeh, S.; Linders, J. B.; Kloskowski, R.; Tanaka, K.; Rubin, B.; Katayama, A.; Kördel, W.; Gerstl, Z.; Lane, M.; Unsworth, J. B. Review pesticide soil sorption parameters: theory, measurement, uses, limitations and reliability. Pest Manage. Sci. 2002, 58, 419-445.

(39) Weber, J. B.; Wilkerson, G. G.; Reinhardt, C. F. Calculating pesticide sorption coefficients (K-d) using selected soil properties. Chemosphere 2004, 55, 157-166.

(40) Dann, R. L.; Close, M. E.; Lee, R.; Pang, L. Impact of data quality and model complexity on prediction of pesticide leaching. $J$. Environ. Qual. 2006, 35, 628-640.

(41) Bernard, H.; Chabalier, P. F.; Chopat, J. L.; Legube, B.; Vauclin, M. Assessment of herbicide leaching risk in two tropical soils of Reunion Island (France). J. Environ. Qual. 2005, $34,534-543$.

(42) Jacobsen, C. S.; Shapir, N.; Jensen, L. O.; Jensen, E. H.; Juhler, R. K.; Streibig, J. C.; Mandelbaum, R. T.; Helweg, A. Bioavail- 
ability of triazine herbicides in a sandy soil profile. Biol. Fertil. Soils 2001, 33, 501-506.

(43) Kristensen, G. B.; Johannesen, H.; Aamand, J. Mineralization of aged atrazine and mecoprop in soil and aquifer chalk. Chemosphere 2001, 45, 927-934.

(44) Regitano, J. B.; Koskinen, W. C.; Sadowsky, M. J. Influence of soil aging on sorption and bioavailability of simazine. J. Agric. Food Chem. 2006, 54, 1373-1379.

(45) García-González, V.; Govantes, F.; Shaw, L. J.; Burns, R. G.; Santero, E. Nitrogen control of atrazine utilization in Pseudomonas sp. strain ADP. Appl. Environ. Microbiol. 2003, 6987-6993.
(46) Shapir, N.; Mandelbaum, R. T.; Fine, P. Atrazine mineralization by indigenous and introduced Pseudomonas sp strain ADP in sand irrigated with municipal wastewater and amended with composted sludge. Soil Biol. Biochem. 2000, 32, 887-897.

Received for review January 11, 2008. Revised manuscript received March 18, 2008. Accepted March 19, 2008. We thank the MEC of Spain for a predoctoral FPI fellowship (for A.C.).

JF800095T 